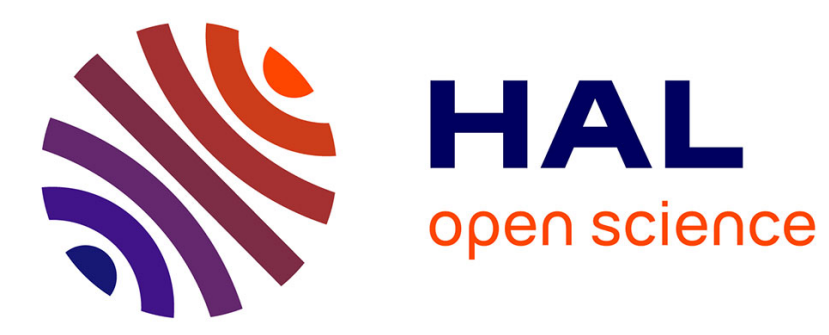

\title{
Oxidation of pentan-2-ol - Part I: Theoretical investigation on the decomposition and isomerization reactions of pentan-2-ol radicals
}

Junfeng Bai, Yuxiang Zhu, Chong-Wen Zhou, Guillaume Dayma, Zeynep Serinyel, Philippe Dagaut

\section{To cite this version:}

Junfeng Bai, Yuxiang Zhu, Chong-Wen Zhou, Guillaume Dayma, Zeynep Serinyel, et al.. Oxidation of pentan-2-ol - Part I: Theoretical investigation on the decomposition and isomerization reactions of pentan-2-ol radicals. Proceedings of the Combustion Institute, 2021, 38 (1), pp.823-832. 10.1016/j.proci.2020.06.194 . hal-03222979

\section{HAL Id: hal-03222979 \\ https://hal.science/hal-03222979}

Submitted on 10 May 2021

HAL is a multi-disciplinary open access archive for the deposit and dissemination of scientific research documents, whether they are published or not. The documents may come from teaching and research institutions in France or abroad, or from public or private research centers.
L'archive ouverte pluridisciplinaire HAL, est destinée au dépôt et à la diffusion de documents scientifiques de niveau recherche, publiés ou non, émanant des établissements d'enseignement et de recherche français ou étrangers, des laboratoires publics ou privés. 


\title{
Oxidation of pentan-2-ol - Part I: Theoretical investigation on the decomposition and isomerization reactions of pentan-2-ol radicals
}

Junfeng Bai ${ }^{1}$, Yuxiang Zhu ${ }^{1}$, Chong-Wen Zhou ${ }^{* 1}$, Guillaume Dayma ${ }^{2,3}$, Zeynep Serinyel ${ }^{2,3}$, Philippe Dagaut $^{2}$

\author{
${ }^{1}$ School of Energy and Power Engineering, Beihang University, Beijing 100191, PR China \\ ${ }^{2}$ CNRS, Institut de Combustion, Aérothermique, Réactivité et Environnement 1C, Avenue de la \\ recherche scientifique, 45071 Orléans cedex 2, France \\ ${ }^{3}$ Université d'Orléans, 6 Avenue du Parc Floral, 45100 Orléans, France
}

Email: cwzhou@buaa.edu.cn

\begin{abstract}
Theoretical investigations on the kinetics of pentan-2-ol radical decomposition and isomerization reactions have been carried out in this work, together with the thermochemistry data calculations for important species involved in the reaction process. The B2PLYPD3/6-311++G(d,p) level of theory was used to optimize the geometries of all of the reactants, transition states, products and also the hindered rotor treatment for lower frequency modes. Single-point energies of all species are determined at the ROCCSD(T) level using the cc-PVQZ and cc-pVTZ which were extrapolated to the complete basis set limit (CBS). RRKM/Master Equation has been solved to calculate the pressure- and temperature-dependent rate coefficients for all channels in the pressure range of $0.01-$ 100 atm over 300-2000 K. Pressure and temperature dependent branching fractions of key species produced from different pentan-2-ol radicals shows that 1- and 2-pentene are important bimolecular products. The kinetics and thermochemistry data for the title reactions has been used in the part II of this work for model development for pentan-2-ol oxidation.
\end{abstract}

Keywords: Pentan-2-ol; Ab initio calculation; Rate constant; Thermodynamics; 


\section{Introduction}

The increasing worldwide demand for sustainable energy resources and environmental protection has brought more and more attention in the research of alternative clean fuels [1-5]. Alcohols have already been considered as sustainable fuel for decades $[6,7]$ and a large number of experimental and theoretical investigations on smaller alcohols have been carried out by different groups. Experimental data of the ignition delay times, laminar flame velocities, species profiles for alcohols from $\mathrm{C}_{1}-\mathrm{C}_{4}$, under a broad range of initial conditions, have been gathered and reorganized in a recent review by Sarathy et al [7]. High-level ab initio calculations on the thermal decomposition reactions of methanol [8], ethanol [9], 2-butanol [10], iso-butanol [11] have been performed, and were found to be in good agreement with the directly measured ones. H-atom abstraction reactions from the alcohol molecule by $\dot{\mathrm{H}}, \dot{\mathrm{OH}}$ and $\mathrm{HO}_{2}$ radicals have also been investigated theoretically, for methanol [12-14], ethanol [9, 15] and butanol isomers [16-18]. Comprehensive mechanisms for the oxidation of methanol and ethanol, with simpler structures, have already been comprehensively reviewed by Sarathy et al. [7]. Man et al. [19] modeled the high temperature oxidation of propanol isomers at temperatures over $1100 \mathrm{~K}$, and conducted shock tube ignition delay time measurements in the temperature range of $1100-1500 \mathrm{~K}$ at pressures from $1.2-16 \mathrm{~atm}$. Sarathy et al. [20] proposed a comprehensive chemical kinetic mechanism for the oxidation of butanol isomers, capable of well reproducing experimental measured species profiles in flames and jet-stirred reactors, laminar flame speeds and shock tube ignition delay times, under a wide range of temperatures and pressures.

Recently, larger alcohols have been the focus of many studies due to their higher energy content [21] and n-pentanol with its higher energy value and reactivity is a promising component for diesel blends [22]. It is reported that n-pentanol could improve the cetane number of diesel blends [23] and decrease CO, hydrocarbon, NOx, smoke and particulate emissions [24-27]. Togbé et al. [28] measured speciation of 1-pentanol oxidation in JSR at 10 atm and laminar flame speeds of 1-pentanol at $423 \mathrm{~K}$ and $1 \mathrm{~atm}$ over equivalence ratios of $0.7-1.4$, and developed a chemical kinetic model to represent their experimental data. Dayma et al. [29] modeled the species 
profiles of iso-pentanol oxidation against the data obtained in a jet-stirred reactor at $10 \mathrm{~atm}$ in the temperature range of 530-1220 K, at equivalence ratios of 0.35-4. Serinyel et al. [30] studied the oxidation of 2-methyl-1-butanol from fuel-lean to fuel-rich mixtures in a jet-stirred reactor at $10 \mathrm{~atm}$, over 700-1200 K, and proposed a mechanism that is also able to predict the ignition delay times and laminar flame speeds of 2-methyl-1-butanol. Theoretical studies have also been performed on the important reaction pathways of pentanol isomers. Van de Vijver et al. [31] computed the pressure- and temperature-dependent rate coefficients for the decomposition and isomerization reaction pathways of 1-pentanol by solving the master equation. Rate constants of the decomposition reactions of 2-pentanol [32], and $\mathrm{H}$-atom abstraction reactions from pentanol isomers by $\dot{\mathrm{OH}}$ radical [33] have also been calculated through theoretical approaches. By far, however, investigations on the combustion process of pentan-2-ol oxidation are quite limited in the literature.

$\mathrm{Li}$ et al. [34] measured Laminar flame speeds of 1-, 2-, and 3-pentanol isomers with air mixtures at equivalence ratios of $0.6-1.8$, with initial pressures of $0.10-0.75 \mathrm{MPa}$, and initial temperatures of 393-473 K employing the outwardly propagating spherical flame. They found the laminar flame speed of 1-pentanol is the fastest, followed by that of 3- and 2-pentanol isomers and the difference between them decreases when pressure increases. Köhler et al. [35] investigated oxidation of 1-, 2- and 3-pentanol doped hydrogen flat flame employing molecular-beam mass spectrometry, and presented the first comparative flame study for 1-, 2- and 3-pentanol with experimental speciation data and kinetic modeling. Van de Vijver et al. [31] have carried out the theoretical investigations on the potential energy surface for decomposition and isomerization reactions of 1-pentanol radicals at UCCSD(T)-F12a/cc-pVTZ-F12//M06-2X/6-311++G(d,p) level of theory and rate coefficients for the reaction channels of interest have been investigated. Pentan-2-ol radicals can be formed through hydrogen atom abstraction reactions by mainly $\mathrm{H}, \mathrm{CH}_{3}$ and $\mathrm{OH}$, from fuel molecules directly, and their subsequent reactions are important in determining the fuel consumption process under different conditions [31]. It is shown that the decomposition and isomerization reactions of 1-pentanol radicals are of significant importance in describing the fuel conversion and 
product selectivity [31]. However, theoretical investigations on the potential energy surface and rate coefficients calculations on pentan-2-ol radicals have not been reported in the literature so far. Thus, this work aims to carry out theoretical calculations on the decomposition and isomerization reactions of pentan-2-ol radicals to provide accurate kinetic data for the model development of pentan-2-ol oxidation which is the part II of this work (in Supplemental Material).

\section{Method}

\subsection{Potential Energy Surface.}

The B2PLYPD3 [36] method with the 6-311++G(d,p) [37] basis set was employed to optimize the geometries of reactants, intermediates, transition states (TSs), and products for all the species involved in the title reactions. Zero-point vibrational energy corrections (ZPE) were calculated at the same level of theory. Single-point energies of all species are determined at the ROCCSD(T) level using the cc-PVQZ and cc-pVTZ [38] which were extrapolated to the complete basis set limit (CBS) [39]:

$$
E_{\mathrm{CBS}}=E_{\mathrm{ROCCSD}(\mathrm{T}) / \mathrm{cc}-\mathrm{pVQZ}}+\left(E_{\mathrm{ROCCSD}(\mathrm{T}) / \mathrm{cc}-\mathrm{pVQZ}}-E_{\mathrm{ROCCSD}(\mathrm{T}) / \mathrm{cc}-\mathrm{pVTZ}}\right) * 4^{4} /\left(5^{4}-4^{4}\right)
$$

The low frequency torsional modes were treated as hindered rotors with their potential scanned at the B2PLYPD3/6-311++G(d,p) level of theory. All geometry optimizations and single point energies are performed with Molpro program [40] and Gaussian 09 [41].

\subsection{Rate Constants Calculations.}

The Master Equation System Solver (MESS) developed by Klippenstein et al. [42] was used to calculate temperature and pressure-dependent rate constants over 300-2000 K and 0.01-100 atm. The interaction between the reactant and $\mathrm{N}_{2}$ bath gas was modeled employing the Lennard-Jones (L-J) potential [43]. For $\mathrm{N}_{2}, \sigma=3.6 \AA$ and $\varepsilon=68 \mathrm{~cm}^{-1}$ were used, while for $\dot{\mathrm{C}}_{5} \mathrm{H}_{11} \mathrm{O}, \sigma=6.269 \AA$ and $\varepsilon=341.3 \mathrm{~cm}^{-1}$ were used [44]. A single-parameter exponential down model with $\left\langle\Delta \mathrm{E}>_{\text {down }}=200 \times(T / 300)^{0.75} \mathrm{~cm}^{-1}\right.$ was used to represent the collisional energy 
transfer function [45]. The calculated rate constants were fitted to a modified Arrhenius expression as a function of temperature $k=A T^{\mathrm{n}} \exp (-E / R T)$.

\subsection{Thermochemistry Calculations.}

The enthalpies of formation at $0 \mathrm{~K}$ for all species are calculated based on atomization approaches, using CBS-APNO[46], CBS-QB3[47], G3[48], and G4[49] composite methods. The $0 \mathrm{~K}$ formation enthalpies, vibrational frequencies, rotational constants and 1-D internal rotational potentials are used as input for the MESS code to calculate temperature-dependent partition functions of each species. With the partition functions, we calculated temperature-dependent thermochemical properties of enthalpies, entropies and heat capacities by calling to the ThermP code $[50,51]$ and converted to NASA polynomial format through PAC99 [50-52].

\section{Results and Discussion}

\subsection{Potential energy surface.}

Potential energy surface for the isomerization and $\beta$-scission reactions of pentanon-2-ol radicals are shown in Figure 1. The addition reaction between ethyl radical and $\mathrm{CH}_{2}=\mathrm{COHCH}_{3}$ forming pentanol2-2 (W1) is treated as the entrance channel. Joint structure treatments were employed for transition states and intermediates that have more than one stable conformer.

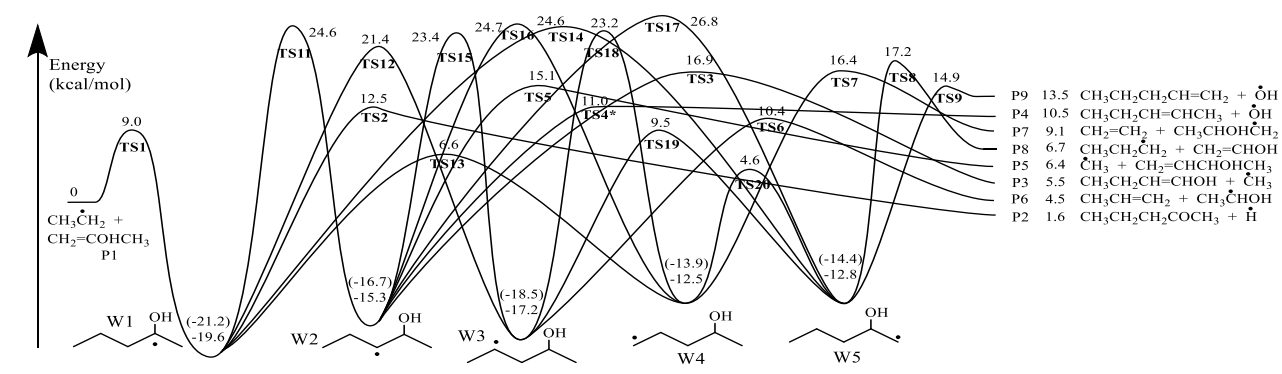

Figure 1. The $\dot{\mathrm{C}}_{5} \mathrm{H}_{11} \mathrm{O}$ potential energy surface (including ZPE) accessed upon isomerization and decomposition of pentan-2-ol radical. Energies are calculated at the ROCCSD(T)//CBS level of theory (kcal/mol).

3.1.1 Isomerization reactions. The isomerization reaction from pentanol2-2 (W1) to pentanol2-5 (W4) with a barrier of $26.2 \mathrm{kcal} / \mathrm{mol}$ is the dominant channel for the consumption of $\mathrm{W} 1$, close to the barrier height for 
pentanol2-4 (W3) to pentanol2-1 (W5) is $26.7 \mathrm{kcal} / \mathrm{mol}$ through a five-membered-ring TS. However, the barrier height for the isomerization process from pentanol2-5 (W4) to pentanol2-1 (W5) is even lower, through a six-membered-ring TS is $17.1 \mathrm{kcal} / \mathrm{mol}$ which is much lower. The barrier heights for other isomerization channels are relatively high, which are more than $30 \mathrm{kcal} / \mathrm{mol}$, via three or four-membered-ring TSs. The radical of pentanol2-3 (W2) could not easily isomerize to other four wells because the barrier heights of isomerization reactions are all higher than $38 \mathrm{kcal} / \mathrm{mol}$.

3.1.2 $\beta$-scission reactions. The most dominant products formed from pentanol2-2 (W1) are ethyl radical and $\mathrm{CH}_{2}=\mathrm{COHCH}_{3}(\mathrm{P} 1)$ with a barrier of $28.6 \mathrm{kcal} / \mathrm{mol}$, the formation of 2-pentanone and $\mathrm{H}(\mathrm{P} 2)$ from W1 with a higher barrier height of $32.1 \mathrm{kcal} / \mathrm{mol}$ is not competitive. The major products formed from pentanol2-3 (W2) are 2-pentene $+\mathrm{OH}(\mathrm{P} 4)$ with a barrier height of $26.3 \mathrm{kcal} / \mathrm{mol}$. It should be noted that the geometries of reaction with *, pentanol2-3 (W2) to 2-pentene $+\mathrm{OH}$ (P4), is calculated by employing BHandHLYP [53] method with the 6-311++G(d,p) basis set, because the transition state could not be located with the B2PLYPD3 method. We use trans structures which have lower energy for 2-pentene in the rate constant calculations. The cis conformer of 2-pentene can also be formed in the decomposition of W2 whose barrier height is $0.8 \mathrm{kcal} / \mathrm{mol}$ higher than that in the trans conformer. The barrier heights for the formation of propyl radical + vinyl alcohol (P8) and 1-pentene + $\mathrm{OH}$ (P9) pentanol2-1 (W5) are 30.0 and $27.7 \mathrm{kcal} / \mathrm{mol}$ respectively with the later reaction channel more competitive. For the decomposition reactions of pentanol2-4 (W3), the formation of propene and $\mathrm{CH}_{3} \mathrm{CHOH}$ (P6) is the most favored channel.

\subsection{Rate Coefficients}

Pressure and temperature dependent rate coefficients have been calculated by using the MESS program [42]. Isomerization and dissociation rate constants and branching ratios for the key reactions discussed above (as a function of temperature at $1 \mathrm{~atm}$ ) are shown in Figure 2-Figure 6. The calculated rate constants and branching ratios over 300-2000 K and $0.01-100$ atm are provided in the Supplemental Material. 

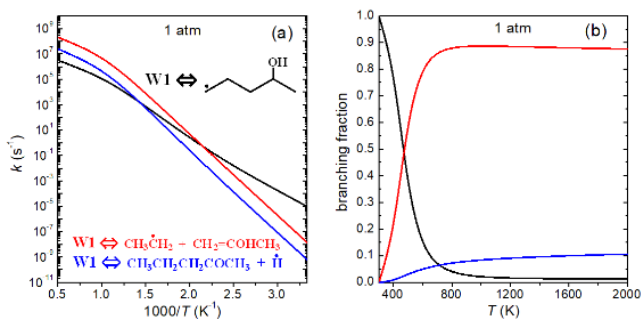

Figure 2 (a) Comparison of rate constants for key reactions from W1 radical and (b) Branching ratios of key products from $\mathrm{W} 1$ radical.

3.2.1 Pentanol2-2 (W1) to products. Rate constants for key reactions from W1 radical and branching ratios of key products from W1 radical are shown in Figure 2. The isomerization reaction of pentanol2-2 (W1) to pentanol2-5 (W4) dominate in the temperature range of 300 to $500 \mathrm{~K}$ through the pressure range we investigated here and this is consistent with the energy barrier calculation. When temperature is above $500 \mathrm{~K}$, the formation of ethyl radical and $\mathrm{CH}_{2}=\mathrm{COHCH}_{3}(\mathrm{P} 1)$ dominates over the pressures of 0.01-100 atm. Notably, at 0.01 atm and when temperature is above $700 \mathrm{~K}$, the branching ratio of pentanol2-1 (W5) is about $5 \%$, which is higher than the formation of pentanol2-5 (W4). However, when pressure goes up to 1 atm, pentanol2-1 (W5) is only of minor importance.
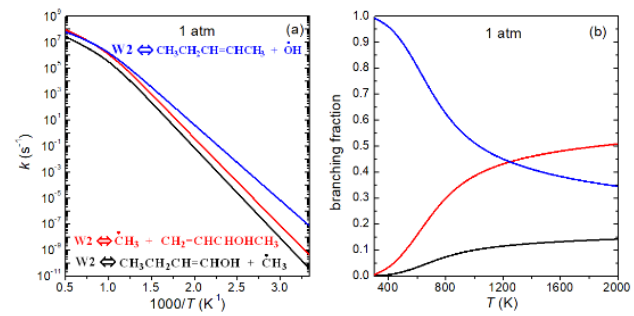

Figure 3 (a) Comparison of rate constants for key reactions from W2 radical and (b) Branching ratios of key products from $\mathrm{W} 2$ radical.

3.2.2 Pentanol2-3 (W2) to products. Rate constants for key reactions from W1 radical and branching ratios of key products from W1 radical are shown in Figure 3. As mentioned above, pentanol2-3 (W2) could not easily isomerize to other four wells given the relatively higher barrier height. The major products are hence $\mathrm{CH}_{3} \mathrm{CH}_{2} \mathrm{CH}=\mathrm{CHOH}^{+}$ $\mathrm{CH}_{3}(\mathrm{P} 3)$, 2-pentene $+\mathrm{OH}(\mathrm{P} 4)$ and $\mathrm{CH}_{3}+\mathrm{CH}_{2}=\mathrm{CHCHOHCH}_{3}(\mathrm{P} 5)$. A strong pressure dependence of the rate constant and branching ratio was observed for those reaction channels. At a lower pressure of $0.01 \mathrm{~atm}$, the formation of 2-pentene $+\mathrm{OH}(\mathrm{P} 4)$ dominates the entire temperature range of this work and the branching ratio of 
$\mathrm{CH}_{3}+\mathrm{CH}_{2}=\mathrm{CHCHOHCH}_{3}$ (P5) is larger than $\mathrm{CH}_{3} \mathrm{CH}_{2} \mathrm{CH}=\mathrm{CHOH}+\mathrm{CH}_{3}(\mathrm{P} 3)$, which is consistent with the barrier height comparison of these three channels. However, when pressure reaches $1 \mathrm{~atm}$ and temperature is above 1200K, the formation of $\mathrm{CH}_{3}+\mathrm{CH}_{2}=\mathrm{CHCHOHCH}_{3}$ (P5) is much favored than 2-pentene $+\mathrm{OH}(\mathrm{P} 4)$. At $100 \mathrm{~atm}$, the branching fraction of $\mathrm{CH}_{3}+\mathrm{CH}_{2}=\mathrm{CHCHOHCH}_{3}$ (P5) is about $60 \%$ at $2000 \mathrm{~K}$. The formation of 2-pentene $+\mathrm{OH}$ dominates at temperatures below $800 \mathrm{~K}$, and its relative importance declines when pressure and temperature is getting higher.
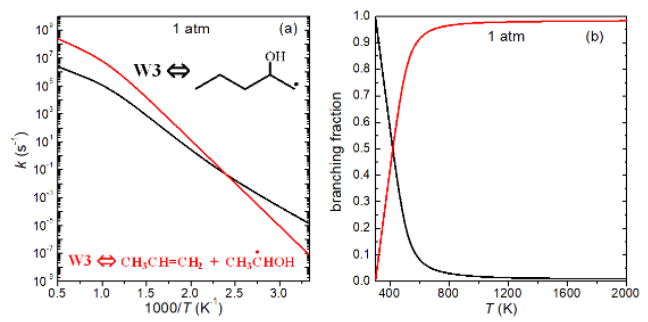

Figure 4 (a) Comparison of rate constants for key reactions from W3 radical and (b) Branching ratios of key products from $\mathrm{W} 3$ radical.

3.2.3 Pentanol2-4 (W3) to products. Rate constants for important reactions from W1 radical and branching ratios of important products from W1 radical are shown in Figure 4. There are two dominating products, pentanol2-1 (W5) and propene and $\mathrm{CH}_{3} \mathrm{CHOH}$ (P6). The branching ratio results do not show strong pressure dependence. Above about $400 \mathrm{~K}$, propene and $\mathrm{CH}_{3} \mathrm{CHOH}(\mathrm{P} 6)$ become the most important products.
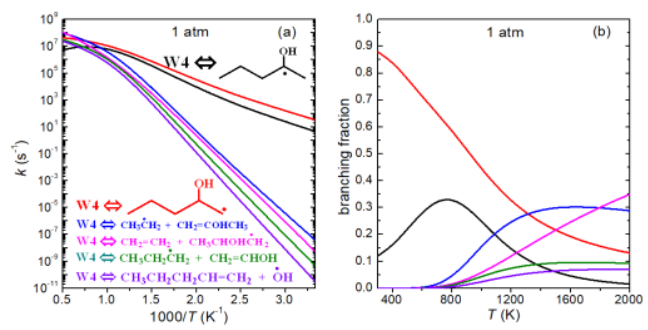

Figure 5 (a) Comparison of rate constants for key reactions from W4 radical and (b) Branching ratios of key products from W4 radical.

3.2.4 Pentanol2-5 (W4) to products. Rate constants and branching ratio for important reactions started from W1 radical are shown in Figure 5. Rate constant and branching ratio results for the formation of ethylene + $\mathrm{CH}_{3} \mathrm{CHOHCH}_{2}$ (P7) also show strong pressure dependence. At $0.01 \mathrm{~atm}$, the formation of pentanol2-1 (W5) is 
dominant when $\mathrm{T}<800 \mathrm{~K}$. At $1 \mathrm{~atm}$, the formation of ethyl radical and $\mathrm{CH}_{2}=\mathrm{COHCH}_{3}(\mathrm{P} 1)$ become dominant in the temperature range of $1300-1800 \mathrm{~K}$. When temperature goes higher than $1800 \mathrm{~K}$, the formation of ethylene + $\mathrm{CH}_{3} \mathrm{CHOHCH}_{2}$ (P7) becomes dominant. When pressure goes up to $100 \mathrm{~atm}$, the formation of ethylene + $\mathrm{CH}_{3} \mathrm{CHOHCH}_{2}$ (P7) becomes dominant when temperature is above $1200 \mathrm{~K}$, and the branching fraction reaches $75 \%$ at $2000 \mathrm{~K}$. At lower pressure of 0.01 and $1 \mathrm{~atm}$, the rate constant of pentanol2-5 (W4) to pentanol2-1 (W5) is higher than pentanol2-2 (W1) in the entire temperature range of interest in this work. However, when pressure goes up to $100 \mathrm{~atm}$, rate constants of pentanol2-5 (W4) to pentanol2-1 (W5) and pentanol2-2 (W1) are almost equal when T > $1100 \mathrm{~K}$. Reaction pathways of pentanol2-5 (W4) to form propyl radical + vinyl alcohol (P8) and 1-pentene $+\mathrm{OH}$ (P9) are of minor importance, with the relative yields both below $10 \%$.
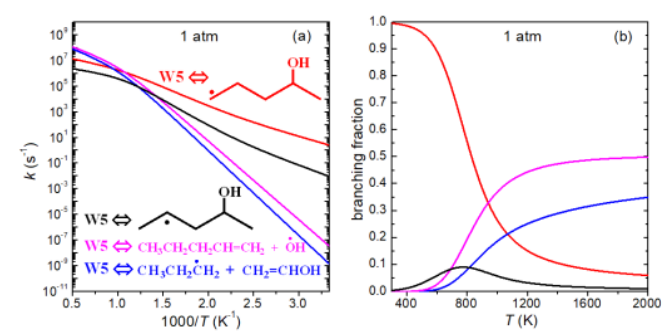

Figure 6 (a) Comparison of rate constants for key reactions from W5 radical and (b) Branching ratios of key products from W5 radical.

3.2.5 Pentanol2-1 (W5) to products. Rate constants for important reactions from W1 radical and branching ratios of important products from W1 radical are shown in Figure 6. At $0.01 \mathrm{~atm}$, the isomerization of pentanol2-1 (W5) to pentanol2-5 (W4) is dominant in the temperature range from 300 to $900 \mathrm{~K}$, which is consistent with the relative barrier height for this reaction process. The formation of pentanol2-2 (W1), ethyl radical and $\mathrm{CH}_{2}=\mathrm{COHCH}_{3}(\mathrm{P} 1)$, propene and $\mathrm{CH}_{3} \mathrm{CHOH}(\mathrm{P} 6)$, are important at $0.01 \mathrm{~atm}$, and become negligible when pressure is higher than $1 \mathrm{~atm}$ over $500-2000 \mathrm{~K}$. The formation of propyl radical + vinyl alcohol (P8) become important at 1 and $100 \mathrm{~atm}$, especially when temperature is above $1000 \mathrm{~K}$. At $1 \mathrm{~atm}$, the formation of 1-pentene $+\mathrm{OH}(\mathrm{P} 9)$ is higher than that of propyl radical + vinyl alcohol (P8) over the entire temperature range, which is consistent with the barrier height comparison. However, the branching ratio becomes equal to $47 \%$ when temperature reaches $2000 \mathrm{~K}$ at $100 \mathrm{~atm}$. 
When temperature is above $1000 \mathrm{~K}$, branching fraction for the formation of 1-pentene $+\mathrm{OH}(\mathrm{P} 9)$ remains around $50 \%$. However, when pressure reaches $100 \mathrm{~atm}$, the formation of 1-pentene $+\mathrm{OH}(\mathrm{P} 9)$ starts to be overwhelmed by that of propyl radical + vinyl alcohol (P8) with temperature above $1200 \mathrm{~K}$.

\subsection{Thermochemistry Calculations.}

Thermochemistry data of $\Delta H_{\mathrm{f}, 298}^{\Theta}, S_{298}^{\Theta}$, and $C_{p}$ for the species in this work was calculated and compared with the ones in the literature, shown in Tables 1 and 2. Literature data come from the Active Thermochemical Tables (ATcT) [54], the Third Millennium Ideal Gas and Condensed Phase Thermochemical Database for Combustion [56] (abbreviated as Burcat's database in this paper), and the NIST Chemistry Webbook [55]. It can be seen that most of our calculated results are in good agreement with the literature data except for few cases. Entropy values for $\mathrm{C}_{2} \mathrm{H}_{5}$ and 2-pentene at $298 \mathrm{~K}$ show relatively larger differences with the values in Burcat's database by 2.4 and 6.7 $\mathrm{cal} / \mathrm{K} \cdot \mathrm{mol}$, respectively. However, the entropy of 2-pentene at $298 \mathrm{~K}$ from our calculation is quite close to the value calculated by Power et al. [57] (within $0.1 \mathrm{cal} / \mathrm{K} \cdot \mathrm{mol}$ ) marked as asterisk in Table 1 . The entropy of pentan-2-ol at $298 \mathrm{~K}$ obtained in this work also differs from the value in Burcat's database by $1.9 \mathrm{cal} / \mathrm{K} \cdot \mathrm{mol}$, but it is closer to the value in NIST Chemistry Webbook (within $0.6 \mathrm{cal} / \mathrm{K} \cdot \mathrm{mol}$ ). For the computed heat capacities at $298 \mathrm{~K}$, results for pentan-2-ol, propen-2-ol and 2-pentene display relatively larger discrepancies with the values in Burcat's database (by $2.2,1.3$ and $2 \mathrm{cal} / \mathrm{K} \cdot \mathrm{mol}$, respectively). Detailed reasons for this discrepancy between the ab initio calculations carried out in this work and the ones in the literature are unclear.

Table 1. Thermochemistry $\left(\Delta H_{\mathrm{f}, 298}^{\Theta}\right.$ and $\left.S_{298}^{\Theta}\right)$ comparison of species on $\mathrm{C}_{5} \mathrm{H}_{11} \dot{\mathrm{O}}$ PES with literature data.

\begin{tabular}{|c|c|l|c|l|}
\hline & \multicolumn{2}{|c|}{$\Delta H_{\mathrm{f}, 298}^{\Theta}\left[\mathrm{kcal} \mathrm{mol}^{-1}\right]$} & \multicolumn{2}{c|}{$S_{298}^{\Theta}\left[\mathrm{cal} \mathrm{K}^{-1} \mathrm{~mol}^{-1}\right]$} \\
\hline Species & This study & \multicolumn{1}{|c|}{ Literature } & This study & \multicolumn{1}{c|}{ Literature } \\
\hline Pentan-2-ol & -75.3 & $\begin{array}{l}-74.7^{\mathrm{b}},-75 \pm 0.3^{\mathrm{b}},-75.2 \pm 0.4^{\mathrm{b}}, \\
75.7 \pm 1.9^{\mathrm{c}}\end{array}$ & 94.5 & $93.7 \pm 0.2^{\mathrm{b}}, 92.1^{\mathrm{c}}$ \\
\hline $\mathrm{C}_{2} \mathrm{H}_{5}$ & 28.7 & $28.7 \pm 0.1^{\mathrm{a}}, 28.4 \pm 0.5^{\mathrm{b}}, 28.6 \pm$ & 60.5 & $58.1^{\mathrm{c}}$ \\
\hline Propen-2-ol (P12) & -40.3 & $\begin{array}{l}-39.3 \pm 0.3^{\mathrm{a}},-42.1^{\mathrm{b}},-38.2 \pm 1.9^{\mathrm{b}}, \\
-39.0 \pm 1.9^{\mathrm{c}}\end{array}$ & 69.7 & $69.9^{\mathrm{c}}$ \\
\hline 2-Pentanone (P21) & -62.3 & $-61.9 \pm 0.3^{\mathrm{b}}$ & 90.9 & \\
\hline 1-Buten-1-ol (P31) & -40.6 & & 81.2 & \\
\hline $\mathrm{CH}_{3}$ & 34.6 & $35.0^{\mathrm{a}}, 34.8^{\mathrm{b}}, 35.1 \pm 0.2^{\mathrm{b}}, 35.1^{\mathrm{c}}$ & 46.5 & $46.4^{\mathrm{b}}, 46.4^{\mathrm{c}}$ \\
\hline 2-Pentene (P41) & -7.1 & $-7.6 \pm 0.5^{\mathrm{b}},-7.3 \pm 1.9^{\mathrm{c}}$ & 81.8 & $88.5^{\mathrm{c}}, 81.9^{*}$ \\
\hline
\end{tabular}




\begin{tabular}{|c|c|c|c|c|}
\hline $\mathrm{OH}$ & 8.9 & $9.0^{\mathrm{a}}, 9.3^{\mathrm{b}}, 8.9 \pm 0.1^{\mathrm{c}}$ & 43.8 & $43.9^{b}, 43.9^{c}$ \\
\hline 3-Buten-2-ol (P52) & -39.5 & & 81.7 & \\
\hline Propene (P61) & 5.0 & $4.8 \pm 0.1^{\mathrm{a}}, 4.9^{\mathrm{b}}, 4.9^{\mathrm{b}}, 4.8 \pm 0.1^{\mathrm{c}}$ & 63.7 & $63.7^{\mathrm{c}}$ \\
\hline Ethanol-1 (P62) & -13.6 & $-13.3 \pm 0.2^{\mathrm{a}},-13.2 \pm 0.1^{\mathrm{c}}$ & 67.8 & $69.1^{\mathrm{c}}$ \\
\hline Ethylene (P71) & 12.6 & $12.5^{\mathrm{a}}, 12.5^{\mathrm{b}}, 12.5 \pm 0.1^{\mathrm{b}}, 12.5^{\mathrm{c}}$ & 52.3 & $52.4^{\mathrm{b}}, 52.4^{\mathrm{c}}$ \\
\hline Isopropyl Alcohol-1 (P72) & -15.3 & & 79.3 & \\
\hline Propane-1 (P81) & 24.0 & $24.1 \pm 0.1^{\mathrm{a}}, 23.9 \pm 0.5^{\mathrm{b}}, 24.2 \pm$ & 70.7 & $69.4^{\mathrm{c}}$ \\
\hline Ethenol (P82) & -29.5 & $\begin{array}{l}-29.6 \pm 0.2^{\mathrm{a}},-30.6^{\mathrm{b}},-29.9 \pm 2.0^{\mathrm{b}} \\
-26.5 \pm 2.0^{\mathrm{b}},-29.8^{\mathrm{c}}\end{array}$ & 62.0 & $62.4^{\mathrm{c}}$ \\
\hline 1-Pentene (P91) & -4.7 & $-5.3 \pm 2.2^{\mathrm{b}},-5.1^{\mathrm{c}}$ & 83.3 & $83.0^{\mathrm{c}}$ \\
\hline Pentanol2-2 (W1) & -32.7 & & 96.1 & \\
\hline Pentanol2-3 (W2) & -27.6 & & 98.2 & \\
\hline Pentanol2-4 (W3) & -30.0 & & 94.5 & \\
\hline Pentanol2-5 (W4) & -25.4 & & 91.5 & \\
\hline Pentanol2-1 (W5) & -25.4 & & 98.3 & \\
\hline
\end{tabular}

${ }^{a}$ Active Thermochemical Tables (Branco Ruscic Argonne National Lab.). [54]

${ }^{b}$ NIST Chemistry Webbook. [55]

${ }^{\mathrm{c}}$ Third Millennium Ideal Gas and Condensed Phase Thermochemical Database for Combustion (Burcat). [56]

Table 2. Thermochemistry $\left(C_{p}\right)$ comparison of species on $\mathrm{C}_{5} \mathrm{H}_{11} \mathrm{O}$ PES with literature data.

\begin{tabular}{|c|c|c|c|c|c|c|c|c|c|c|c|c|c|c|}
\hline \multirow[b]{3}{*}{ Species } & \multicolumn{14}{|c|}{$C_{p}(\mathrm{~T})\left[\mathrm{cal} \mathrm{K}^{-1} \mathrm{~mol}^{-1}\right]$} \\
\hline & \multicolumn{7}{|c|}{ This Study } & \multicolumn{7}{|c|}{ Literature } \\
\hline & 300 & 400 & 500 & 600 & 800 & 1000 & 1500 & 300 & 400 & 500 & 600 & 800 & 1000 & 1500 \\
\hline Pentan-2-ol & 33.2 & 40.5 & 47.5 & 53.7 & 63.1 & 70.3 & 81.7 & $31.0^{\mathrm{c}}$ & & & & & & \\
\hline Pentanol2-2 (W1) & 32.9 & 39.9 & 46.4 & 52.1 & 60.6 & 67.1 & 77.3 & & & & & & & \\
\hline Pentanol2-3 (W2) & 34.2 & 40.2 & 46.1 & 51.4 & 59.8 & 66.4 & 76.8 & & & & & & & \\
\hline Pentanol2-4 (W3) & 32.3 & 39.4 & 46.2 & 52.1 & 60.9 & 67.6 & 78.0 & & & & & & & \\
\hline Pentanol2-5 (W4) & 36.1 & 44.0 & 50.2 & 55.3 & 63.1 & 69.0 & 78.7 & & & & & & & \\
\hline Pentanol2-1 (W5) & 33.8 & 40.6 & 46.8 & 52.3 & 60.7 & 67.1 & 77.2 & & & & & & & \\
\hline $\mathrm{C} 2 \mathrm{H} 5$ (P11) & 12.1 & 14.5 & 16.9 & 19.1 & 22.6 & 25.4 & 29.9 & $12.1^{\mathrm{c}}$ & & & & & & \\
\hline Propen-2-ol (P12) & 20.5 & 25.1 & 28.9 & 31.9 & 36.3 & 39.7 & 45.1 & $19.2^{\mathrm{c}}$ & & & & & & \\
\hline 2-Pentanone (P21) & 28.6 & 35.3 & 41.7 & 47.3 & 56.0 & 62.6 & 72.9 & $28.5^{\mathrm{b}}$ & 36.4 & 42.6 & & & & \\
\hline 1-Buten-1-ol (P31) & 24.3 & 30.0 & 35.2 & 39.7 & 46.2 & 51.1 & 58.9 & & & & & & & \\
\hline \multirow[t]{2}{*}{$\mathrm{CH} 3$ (P32) } & 9.4 & 10.1 & 10.8 & 11.5 & 12.8 & 13.9 & 16.1 & $9.3^{\mathrm{b}}$ & 10.1 & 10.8 & 11.5 & 12.9 & 14.1 & 16.3 \\
\hline & & & & & & & & $9.2^{\mathrm{c}}$ & & & & & & \\
\hline \multirow[t]{2}{*}{ 2-Pentene (P41) } & 26.0 & 32.1 & 38.0 & 43.3 & 51.6 & 58.0 & 68.0 & $26.1^{\mathrm{b}}$ & 32.6 & 38.7 & 44.0 & 52.6 & 59.0 & 68.9 \\
\hline & & & & & & & & $24.0^{\mathrm{c}}$ & & & & & & \\
\hline \multirow[t]{2}{*}{$\mathrm{OH}(\mathrm{P} 42)$} & 7.2 & 7.1 & 7.0 & 7.0 & 7.1 & 7.2 & 7.7 & $7.2^{\mathrm{b}}$ & 7.1 & 7.1 & 7.1 & 7.2 & 7.3 & 7.9 \\
\hline & & & & & & & & $7.1^{\mathrm{c}}$ & & & & & & \\
\hline 3-Buten-2-ol (P52) & 27.4 & 32.9 & 37.4 & 41.1 & 47.0 & 51.6 & 59.1 & & & & & & & \\
\hline \multirow[t]{3}{*}{ Propene (P61) } & 15.1 & 18.7 & 22.2 & 25.3 & 30.2 & 34.0 & 39.9 & $15.4^{\mathrm{b}}$ & 19.2 & 22.7 & 25.8 & 30.8 & 34.5 & 40.4 \\
\hline & & & & & & & & $15.5^{\mathrm{b}}$ & 19.2 & 22.6 & & & & \\
\hline & & & & & & & & $15.4^{\mathrm{c}}$ & & & & & & \\
\hline Ethanol-1 (P62) & 15.7 & 18.6 & 21.4 & 23.8 & 27.7 & 30.6 & 35.4 & $15.3^{\mathrm{c}}$ & & & & & & \\
\hline \multirow[t]{4}{*}{ Ethylene (P71) } & 10.2 & 12.4 & 14.7 & 16.7 & 19.7 & 22.1 & 26.0 & $10.3^{\mathrm{b}}$ & 12.7 & 14.9 & 16.9 & 20.1 & 22.4 & 26.3 \\
\hline & & & & & & & & $10.4^{\mathrm{b}}$ & 12.6 & 15.2 & & & & \\
\hline & & & & & & & & $10.3^{\mathrm{b}}$ & 12.7 & 14.9 & 16.9 & 20.0 & 22.4 & 26.3 \\
\hline & & & & & & & & $10.3^{\mathrm{c}}$ & & & & & & \\
\hline Isopropyl Alcohol-1(P72) & 22.3 & 26.5 & 30.3 & 33.5 & 38.6 & 42.4 & 48.8 & & & & & & & \\
\hline
\end{tabular}




\begin{tabular}{|l|l|l|l|l|l|l|l|l|l|l|l|l|l|l|}
\hline Propane-1 (P81) & 17.1 & 21.1 & 24.9 & 28.2 & 33.4 & 37.5 & 44.0 & $17.0^{\mathrm{c}}$ & & & & & & \\
\hline Ethenol (P82) & 15.0 & 18.0 & 20.5 & 22.5 & 25.4 & 27.5 & 31.0 & $14.9^{\mathrm{c}}$ & & & & & & \\
\hline 1-Pentene (P91) & 26.0 & 32.4 & 38.5 & 43.9 & 52.0 & 58.4 & 68.2 & $26.0^{\mathrm{b}}$ & 32.9 & 39.2 & 44.5 & 52.8 & 58.8 & 68.2 \\
\hline & & & & & & & & $25.9^{\mathrm{c}}$ & & & & & & \\
\hline
\end{tabular}

\section{Conclusion}

Theoretical rate constants and thermochemistry investigations on pyrolysis of pentan-2-ol radicals have been carried out in this work. According to the barrier height for bimolecular products, ethyl radical and $\mathrm{CH}_{2}=\mathrm{COHCH}_{3}$ (P1), 2-pentene $+\mathrm{OH}(\mathrm{P} 4)$ and 1-pentene $+\mathrm{OH}(\mathrm{P} 9)$ are found to be the more favorable products from different isomers.

Strong pressure and temperature dependence has been shown in the rate constants calculations for the title reactions. The formation of 2-pentene $+\mathrm{OH}(\mathrm{P} 4)$ is dominant at temperatures below $800 \mathrm{~K}$ and pressures below 10 atm. However, as pressure increases, the dominant zone of the formation of 1-pentene $+\mathrm{OH}$ (P9) shifts to higher temperatures. Thermochemistry data for the species involved in this work has been calculated and compared with the ones in the literature. Most of our results show good agreement with literature data, except for some species such as 2-pentene, pentan-2-ol and propen-2-ol, the reason of it is unclear so far. This work provides new kinetics and thermodynamics data for decomposition and isomerization reactions of pentan-2-ol radicals which was used in the model development for pentan-2-ol oxidation (part II of this work).

\section{Acknowledgments}

Chong-Wen Zhou acknowledges the funding support from National Science and Technology Major Project (2017-III0004-0028) and National Science Foundation of China (NSFC) under grant number 91841301. Guillaume Dayma, Zeynep Serinyel and Philippe Dagaut would like to acknowledge the funding received from Labex Caprysses (convention ANR-11-LABX-0006-01).

\section{Reference}

[1] A.K. Agarwal, Biofuels (alcohols and biodiesel) applications as fuels for internal combustion engines, Progress in Energy and Combustion Science, 33 (2007) 233-271. 
[2] G. Black, H.J. Curran, S. Pichon, J.M. Simmie, V. Zhukov, Bio-butanol: Combustion properties and detailed chemical kinetic model, Combustion and Flame, 157 (2010) 363-373.

[3] M. Gautam, D.W. Martin, Combustion characteristics of higher-alcohol/gasoline blends, Proceedings of the Institution of Mechanical Engineers, Part A: Journal of Power and Energy, 214 (2005) 497-511.

[4] G.P. Robertson, S.K. Hamilton, B.L. Barham, B.E. Dale, R.C. Izaurralde, R.D. Jackson, D.A. Landis, S.M. Swinton, K.D. Thelen, J.M. Tiedje, Cellulosic biofuel contributions to a sustainable energy future: Choices and outcomes, Science, 356 (2017).

[5] J.M. Bergthorson, M.J. Thomson, A review of the combustion and emissions properties of advanced transportation biofuels and their impact on existing and future engines, Renewable and Sustainable Energy Reviews, 42 (2015) 1393-1417.

[6] K. Kohse-Hoinghaus, P. Osswald, T.A. Cool, T. Kasper, N. Hansen, F. Qi, C.K. Westbrook, P.R. Westmoreland, Biofuel combustion chemistry: from ethanol to biodiesel, Angew Chem Int Ed Engl, 49 (2010) 3572-3597.

[7] S.M. Sarathy, P. Oßwald, N. Hansen, K. Kohse-Höinghaus, Alcohol combustion chemistry, Prog. Energy Combust. Sci., 44 (2014) 40-102.

[8] A.W. Jasper, S.J. Klippenstein, L.B. Harding, B. Ruscic, Kinetics of the reaction of methyl radical with hydroxyl radical and methanol decomposition, J. Phys. Chem. A, 111 (2007) 3932-3950.

[9] R. Sivaramakrishnan, M.-C. Su, J. Michael, S. Klippenstein, L. Harding, B. Ruscic, Rate constants for the thermal decomposition of ethanol and its bimolecular reactions with $\mathrm{OH}$ and $\mathrm{D}$ : reflected shock tube and theoretical studies, J. Phys. Chem. A, 114 (2010) 9425-9439.

[10] A.M. El-Nahas, A.H. Mangood, H. Takeuchi, T. Taketsugu, Thermal decomposition of 2-butanol as a potential nonfossil fuel: a computational study, J. Phys. Chem. A, 115 (2011) 2837-2846.

[11] C.-W. Zhou, S.J. Klippenstein, J.M. Simmie, H.J. Curran, Theoretical kinetics for the decomposition of iso-butanol and related $(\mathrm{CH} 3) 2 \dot{\mathrm{C}} \mathrm{H}+\dot{\mathrm{C}} \mathrm{H} 2 \mathrm{OH}$ reactions, Proc. Combust. Inst., 34 (2013) 501-509.

[12] R. Meana-Pañeda, D.G. Truhlar, A. Fernández-Ramos, High-level direct-dynamics variational transition state theory calculations including multidimensional tunneling of the thermal rate constants, branching ratios, and kinetic isotope effects of the hydrogen abstraction reactions from methanol by atomic hydrogen, J. Chem. Phys., 134 (2011) 094302.

[13] S. Xu, M. Lin, Theoretical study on the kinetics for $\mathrm{OH}$ reactions with $\mathrm{CH} 3 \mathrm{OH}$ and $\mathrm{C} 2 \mathrm{H} 5 \mathrm{OH}$, Proc. Combust. Inst., 31 (2007) 159-166.

[14] S.J. Klippenstein, L.B. Harding, M.J. Davis, A.S. Tomlin, R.T. Skodje, Uncertainty driven theoretical kinetics studies for $\mathrm{CH} 3 \mathrm{OH}$ ignition: $\mathrm{HO} 2+\mathrm{CH} 3 \mathrm{OH}$ and $\mathrm{O} 2+\mathrm{CH} 3 \mathrm{OH}$, Proc. Combust. Inst., 33 (2011) 351-357.

[15] J. Zheng, D.G. Truhlar, Multi-path variational transition state theory for chemical reaction rates of complex polyatomic species: ethanol+ OH reactions, Faraday Discuss., 157 (2012) 59-88.

[16] P. Seal, G. Oyedepo, D.G. Truhlar, Kinetics of the hydrogen atom abstraction reactions from 1-butanol by hydroxyl radical: theory matches experiment and more, J. Phys. Chem. A, 117 (2013) 275-282.

[17] C.W. Zhou, J.M. Simmie, H.J. Curran, Rate constants for hydrogen abstraction by HÖ2 from n-butanol, Int. J. Chem. Kinet., 44 (2012) 155-164.

[18] C.-W. Zhou, J.M. Simmie, H.J. Curran, Rate constants for hydrogen-abstraction by O` H from n-butanol, Combust. Flame, 158 (2011) 726-731.

[19] X. Man, C. Tang, J. Zhang, Y. Zhang, L. Pan, Z. Huang, C.K. Law, An experimental and kinetic modeling study of n-propanol and i-propanol ignition at high temperatures, Combustion and Flame, 161 (2014) 644-656.

[20] S.M. Sarathy, S. Vranckx, K. Yasunaga, M. Mehl, P. Oßwald, W.K. Metcalfe, C.K. Westbrook, W.J. Pitz, K. Kohse-Höinghaus, R.X. Fernandes, A comprehensive chemical kinetic combustion model for the four butanol isomers, Combust. Flame, 159 (2012) 2028-2055.

[21] C. Tang, L. Wei, X. Man, J. Zhang, Z. Huang, C.K. Law, High temperature ignition delay times of C5 primary alcohols, Combustion and Flame, 160 (2013) 520-529. 
[22] J. Campos-Fernandez, J.M. Arnal, J. Gomez, N. Lacalle, M.P. Dorado, Performance tests of a diesel engine fueled with pentanol/diesel fuel blends, Fuel, 107 (2013) 866-872.

[23] H.K. Imdadul, H.H. Masjuki, M.A. Kalam, N.W.M. Zulkifli, A. Alabdulkarem, M.M. Rashed, A.M. Ashraful, Influences of ignition improver additive on ternary (diesel-biodiesel-higher alcohol) blends thermal stability and diesel engine performance, Energy Conversion and Management, 123 (2016) 252-264.

[24] B. Rajesh Kumar, S. Saravanan, D. Rana, A. Nagendran, Combined effect of injection timing and exhaust gas recirculation (EGR) on performance and emissions of a DI diesel engine fuelled with next-generation advanced biofuel diesel blends using response surface methodology, Energy Conversion and Management, 123 (2016) 470-486.

[25] L. Wei, C.S. Cheung, Z. Huang, Effect of n-pentanol addition on the combustion, performance and emission characteristics of a direct-injection diesel engine, Energy, 70 (2014) 172-180.

[26] Z.-H. Zhang, S.-M. Chua, R. Balasubramanian, Comparative evaluation of the effect of butanol-diesel and pentanol-diesel blends on carbonaceous particulate composition and particle number emissions from a diesel engine, Fuel, 176 (2016) 40-47.

[27] L. Li, J. Wang, Z. Wang, J. Xiao, Combustion and emission characteristics of diesel engine fueled with diesel/biodiesel/pentanol fuel blends, Fuel, 156 (2015) 211-218.

[28] C. Togbé, F. Halter, F. Foucher, C. Mounaim-Rousselle, P. Dagaut, Experimental and detailed kinetic modeling study of 1-pentanol oxidation in a JSR and combustion in a bomb, Proceedings of the Combustion Institute, 33 (2011) 367-374.

[29] G. Dayma, C. Togbé, P. Dagaut, Experimental and Detailed Kinetic Modeling Study of Isoamyl Alcohol (Isopentanol) Oxidation in a Jet-Stirred Reactor at Elevated Pressure, Energy \& Fuels, 25 (2011) 4986-4998.

[30] Z. Serinyel, C. Togbé, G. Dayma, P. Dagaut, An experimental and modeling study of 2-methyl-1-butanol oxidation in a jet-stirred reactor, Combustion and Flame, 161 (2014) 3003-3013.

[31] R. Van de Vijver, K.M. Van Geem, G.B. Marin, J. Zádor, Decomposition and isomerization of 1-pentanol radicals and the pyrolysis of 1-pentanol, Combustion and Flame, 196 (2018) 500-514.

[32] A. Parandaman, B. Rajakumar, Thermal Decomposition of 2-Pentanol: A Shock Tube Study and RRKM Calculations, J. Phys. Chem. A, 120 (2016) 8024-8036.

[33] B. Aazaad, S. Lakshmipathi, Reaction of Pentanol isomers with OH radical-A theoretical perspective, Mol. Phys., 116 (2018) 1153-1165.

[34] Q. Li, E. Hu, X. Zhang, Y. Cheng, Z. Huang, Laminar Flame Speeds and Flame Instabilities of Pentanol Isomer-Air Mixtures at Elevated Temperatures and Pressures, Energy \& Fuels, 27 (2013) 1141-1150.

[35] M. Köhler, T. Kathrotia, P. Oßwald, M.L. Fischer-Tammer, K. Moshammer, U. Riedel, 1-, 2- and 3-Pentanol combustion in laminar hydrogen flames - A comparative experimental and modeling study, Combustion and Flame, 162 (2015) 3197-3209.

[36] S. Grimme, Semiempirical hybrid density functional with perturbative second-order correlation, J Chem Phys, 124 (2006) 034108.

[37] A.D. McLean, G.S. Chandler, Contracted Gaussian basis sets for molecular calculations. I. Second row atoms, $Z=11-18$, The Journal of Chemical Physics, 72 (1980) 5639-5648.

[38] T.H. Dunning, Gaussian basis sets for use in correlated molecular calculations. I. The atoms boron through neon and hydrogen, The Journal of Chemical Physics, 90 (1989) 1007-1023.

[39] J.M.L. Martin, Ab Initio Total Atomization Energies of Small Molecules --Towards the Basis Set Limit. , Chem. Phys. Lett., 259 (1996) 10.

[40] A.B. R. D. Amos, A. Berning, P. Celani, D. L. Cooper, M. J. O. Deegan, A. J. Dobbyn, F. Eckert, C. Hampel, G. Hetzer, P. J. Knowles, T. Korona, R. Lindh, A. W. Lloyd, S. J. McNicholas, F. R. Manby, W. Meyer, M. E. Mura, A. Nicklass, P. Palmieri, R. Pitzer, G. Rauhut, M. Schu“ tz, U. Schumann, H. Stoll, A. J. Stone, R. Tarroni, T. Thorsteinsson and H.-J. Werner, MOLPRO, a package of ab initio programs designed by H.-J. Werner and P. J. Knowles, (2015). 
[41] J. Foresman, J.C. Ortiz, J, D. Fox, Gaussian 09, Revision D. 01; Gaussian, Inc.: Wallingford, CT, (2009).

[42] J.A. Miller, S.J. Klippenstein, Master equation methods in gas phase chemical kinetics, J Phys Chem A, 110 (2006) 10528-10544.

[43] M.J. Pilling, S.H. Robertson, Master equation models for chemical reactions of importance in combustion, Annu Rev Phys Chem, 54 (2003) 245-275.

[44] F.M. Mourits, F.H.A. Rummens, A critical evaluation of Lennard-Jones and Stockmayer potential parameters and of some correlation methods, Can. J. Chem., 55 (1977) 3007-3020.

[45] S.J. Klippenstein, J.A. Miller, The addition of hydrogen atoms to diacetylene and the heats of formation of i-C4H3 and n-C4H3, J Phys Chem A, 109 (2005) 4285-4295.

[46] J.W. Ochterski, G.A. Petersson, J.A. Montgomery, A complete basis set model chemistry. V. Extensions to six or more heavy atoms, The Journal of Chemical Physics, 104 (1996) 2598-2619.

[47] J.A. Montgomery, M.J. Frisch, J.W. Ochterski, G.A. Petersson, A complete basis set model chemistry. VII. Use of the minimum population localization method, The Journal of Chemical Physics, 112 (2000) 6532-6542.

[48] L.A. Curtiss, K. Raghavachari, P.C. Redfern, V. Rassolov, J.A. Pople, Gaussian-3 (G3) theory for molecules containing first and second-row atoms, The Journal of Chemical Physics, 109 (1998) 7764-7776.

[49] L.A. Curtiss, P.C. Redfern, K. Raghavachari, Gaussian-4 theory, J Chem Phys, 126 (2007) 084108.

[50] M. Keçeli, S.N. Elliott, Y.-P. Li, M.S. Johnson, C. Cavallotti, Y. Georgievskii, W.H. Green, M. Pelucchi, J.M. Wozniak, A.W. Jasper, S.J. Klippenstein, Automated computational thermochemistry for butane oxidation: A prelude to predictive automated combustion kinetics, Proceedings of the Combustion Institute, 37 (2019) 363-371.

[51] S.J.K. Murat Keceli, B.J. McBride, S. Gordon, Quantum Thermochemistry Calculator (Qtc), 2018

[52] B.J. McBride, S. Gordon, Computer Program for Calculating and Fitting Thermodynamic Functions, 1992

[53] A.D. Becke, A new mixing of Hartree-Fock and local density-functional theories, The Journal of Chemical Physics, 98 (1993) 1372-1377.

[54] B. Ruscic, D. Bross, Active Thermochemical Tables (ATcT) values based on ver. 1.122d of the Thermochemical Network, 2018

[55] E. Lemmon, M. McLinden, D. Friend, P. Linstrom, W. Mallard, NIST Chemistry Webbook, NIST Standard Reference Database Number 69, National Institute of Standards and Technology: Gaithersburg, 2011

[56] A. Burcat, B. Ruscic, Third Millennium Ideal Gas and Condensed Phase Thermochemical Database for Combustion (with Update from Active Thermochemical Tables), Argonne National Labarotary (ANL): Argonne, IL (United States), 2005

[57] J. Power, K.P. Somers, C.W. Zhou, S. Peukert, H.J. Curran, Theoretical, Experimental, and Modeling Study of the Reaction of Hydrogen Atoms with 1- and 2-Pentene, J Phys Chem A, 123 (2019) 8506-8526. 